OPEN

CONFERENCE PROCEEDINGS

ISFM2014

..............

\author{
SUBJECT AREAS: \\ SYNTHESIS AND \\ PROCESSING \\ NANOWIRES \\ SOLAR CELLS \\ SOLAR ENERGY AND \\ PHOTOVOLTAIC \\ TECHNOLOGY
}

Received

29 April 2014

Accepted

8 July 2014

Published

23 March 2015

Correspondence and requests for materials should be addressed to H.W. (nanoguy@126. com) or B.W.

(baoyuanw@163.

com)

\section{Significant enhancement of power} conversion efficiency for dye sensitized solar cell using 1D/3D network nanostructures as photoanodes

\author{
Hao Wang, Baoyuan Wang, Jichao Yu, Yunxia Hu, Chen Xia, Jun Zhang \& Rong Liu
}

Hubei Collaborative Innovation Center for Advanced Organic Chemical Materials, Faculty of Physics and Electronic Science, Hubei University, Wuhan 430062, PR China.

The single-crystalline $\mathrm{TiO}_{2}$ nanorod arrays with rutile phase have attracted much attention in the dye sensitized solar cells (DSSCs) applications because of their superior chemical stability, better electron transport properties, higher refractive index and low production cost. However, it suffers from a low surface area as compared with $\mathrm{TiO}_{2}$ nanoparticle films. In order to enlarge the surface area of $\mathrm{TiO}_{2}$ nanorod arrays, the $1 \mathrm{D}$ nanorods/3D nanotubes sample was synthesized using a facile two-step hydrothermal process involving hydrothermal growth 1D/3D nanorods and followed by post-etching treatment. In such bi-layer structure, the oriented $\mathrm{TiO}_{2}$ nanorods layer could provide direct pathway for fast electron transportation, and the 3D nanotubes layer offers a higher surface area for dye loading, therefore, the $1 \mathrm{D}$ nanorods/3D nanotubes photoanode exhibited faster electron transport and higher surface area than either 1D or 3D nanostructures alone, and an highest efficiency of $7.68 \%$ was achieved for the DSSCs based on 1D nanorods/ $3 \mathrm{D}$ nanotubes photoanode with further $\mathrm{TiCl}_{4}$ treatment.

D ye-sensitized solar cells (DSSCs) have attracted extensive research attention due to its low-cost, highefficiency, and non-pollution, it has been considered as one of the most promising alternatives to Si-based photovoltaic cells in the last two decades ${ }^{1-3}$. Typically, DSSCs consists of nanoporous $\mathrm{TiO}_{2}$ films, a monolayer of dye molecule, counter electrode, and $\mathrm{I}^{-} / \mathrm{I}^{3-}$ redox electrolyte solution. Among them, $\mathrm{TiO}_{2}$ films serves as the transport media for photo-generated electrons and take charge for dye-loading and charge-collection ${ }^{4,5}$. Therefore, the shape and structure of $\mathrm{TiO}_{2}$ layer play an importance role in the photoperformance of DSSCs, and continuous efforts have been made for synthesizing different structure of $\mathrm{TiO}_{2}$ photoanode to improving the PCE of solar cells. The $\mathrm{TiO}_{2}$ films with shape of cactus-like ${ }^{6}$, treelike, forest-like ${ }^{8}$, pine tree-like ${ }^{9}$ have been successfully synthesized and applied as photoanode in DSSCs, these exhibited dramatic potential in improving performance for applications in solar cells.

Recently, $\mathrm{TiO}_{2}$ photoanode with $1 \mathrm{D} / 3 \mathrm{D}$ bi-layer structure have attracted much attention, such a structure may render fewer grain boundaries, larger surface area and better light scattering properties. For example, Hong et al. ${ }^{10}$ synthesized $1 \mathrm{D}$ vertically aligned rutile $\mathrm{TiO}_{2}$ nanorods and $3 \mathrm{D} \mathrm{TiO}{ }_{2}$ nanostars by a single step hydrothermal route, the $3 \mathrm{D}$ nanostars/1D nanorods based DSSCs cell exhibited 5.39\% power conversion efficiency ( $\eta$ ), which is remarkably higher than that of bare $1 \mathrm{D}$ nanorods based (3.74\%) photoelectrode. Wang et al. ${ }^{11}$ reported a new type of crystalline rutile $\mathrm{TiO}_{2}$ nanorod based photoanode prepared by using a facile two step hydrothermal process, the bilayer photoanode has a bottom layer composed of oriented single-crystalline rutile nanorods and a top layer composed of loosely packed nanorods which not only increases the dye loading with a significantly increased surface area but also improves light scattering without sacrificing the electron-transport efficiency. Therefore, the resultant new structures delivered light-to-electricity conversion efficiency of $6.31 \%$ as photoanodes in DSSCs. Kim et al. ${ }^{12}$ reported $1 \mathrm{D} / 3 \mathrm{D}$ nanorod network consisting of $1 \mathrm{D}$ nanowires bottom arrays and a three-dimensional (3D) dendritic microsphere top layer. These bilayer nanostructures simultaneous possess the incompatible features such as high specific area, fast electron transport, and a pronounced light-scattering effect, and demonstrated a high energy conversion efficiency of 5.6\%. In addition, as we known, nanotubes structure ${ }^{13-15}$ exhibited bigger specific surface area than that of nanorod ${ }^{16-18}$. Shao et al. ${ }^{19}$ reported $3 \mathrm{D}$ porous architecture composed of 
$\mathrm{TiO}_{2}$ nanotubes shown a large surface area of $502.9 \mathrm{~m}^{2} \mathrm{~g}^{-1}$ has been obtained. So the transformation nanorods into nanotubes is a available method for largenning the surface area.

In this work, a novel $1 \mathrm{D}$ nanorods/3D nanotubes network structure was synthesized on a transparent conducting oxide substrates (TCO) by two-step hydrothermal. Relative to previous work and other related works ${ }^{11-13}$, the $1 \mathrm{D}$ nanorod/3D nanotubes network structure was proposed as a derived structure of $1 \mathrm{D} / 3 \mathrm{D}$ nanorod network. Compared with the nanorod network, the 1D nanorod/ 3D nanotubes network structure exhibited obvious advantages of larger specific surface area, due to the hollow of the 3D nanotubes. To the best of our knowledge, there is no report on $1 \mathrm{D}$ nanorod/3D nanotubes for DSSCs. The new structures delivered the highest power conversion efficiency of $7.68 \%$ to date for the DSSCs based on $1 \mathrm{D}$ rutile $\mathrm{TiO}_{2}$ nanorods photoanodes with further $\mathrm{TiCl}_{4}$ treatment. In addition, we have compared the photovoltaic performance of $1 \mathrm{D}$ nanorods/3D nanotubes structure with $3 \mathrm{D}$ nanotubes photoanode, and the detailed transient properties and electron transport resistance of these network structure in DSSCs were analyzed by open circuit voltage decay (OCVD) measurements and electrochemical impedance spectra (EIS), the 1D nanorods/3D nanotubes sample exhibits superior characteristics with longer life time and smaller electron transport resistance, indicating rapider electron transport rate than $3 \mathrm{D}$ nanotubes sample, which attributed to the electron pathway provided by $1 \mathrm{D}$ nanorod arrays.

\section{Results and Discussion}

Figure 1 shows field emission scanning electron microscopy (FESEM) and transmission electron microscopy (TEM) images of $1 \mathrm{D} / 3 \mathrm{D} \mathrm{TiO}_{2}$ nanorods prepared by hydrothermal method using a solution of $0.9 \mathrm{ml}$ titanium butoxide, $16 \mathrm{ml}$ hydrochloric acid, $16 \mathrm{ml}$ deionized water at $150^{\circ} \mathrm{C}$ for $10 \mathrm{~h}$ while the FTO substrate lied flat on the bottom of the reactor with the conductive side facing up. Figure 1 (a) shows the cross-sectional SEM image of the sample. As the image shown, after a single-step hydrothermal synthesis, a bi-layer network nanostructure has been formed, which consists of the upper layer of $3 \mathrm{D} \mathrm{TiO} 2$ nanorods and the bottom layer of $1 \mathrm{D} \mathrm{TiO}{ }_{2}$ nanorod arrays. The figure 1 (b) and the inset of figure 1(b) present the cross-sectional and top views of the $1 \mathrm{D}$ nanorod arrays, respectively. It reveals that the $1 \mathrm{D} \mathrm{TiO}_{2}$ nanorod arrays are very dense and little space exists between adjacent $\mathrm{TiO}_{2}$ nanorods. The average length of the nanorods is $\sim 4.4 \mu \mathrm{m}$ with the average diameter of $150 \mathrm{~nm}$. In addition, it can be seen from the plan view of 3D nanorods layer (figure 1c) that the upper layer of the superstructure consists of $\mathrm{TiO}_{2}$ flower-like clusters. A close-up of a flower looks like a natural chrysanthemum. Each flower was composed of a large number of nanorods, and every individual nanorod is tetragonal in shape with square top facets. The void in the bottom nanorod arrays provide nucleation site for the upper 3D nanorods layer, which grow randomly and subsequently form a flow-like structure. These spokewise nanorods radiated from a common central zone. The nanorods were roughly $3 \mu \mathrm{m}$ long and $450 \mathrm{~nm}$ wide with an aspect ratio of about 6.7. Moreover, the top surface of a nanorod appeared to contain many step edges, which are the substrates for further growth of sub-nanorods, while the side surface was smooth. Clearly a fully grown flower possessed a spherical symmetry with an average diameter of approximately $7.5 \mu \mathrm{m}$. From the SEM image at low magnification (Figure1 d), the $\mathrm{TiO}_{2}$ flower-like clusters uniformly distributed on the surface of substrate, and enough space emerged between two adjacent $\mathrm{TiO}_{2}$ clusters which are benefit for dye loading. Moreover, during the hydrothermal process, while the FTO substrate lied flat on the bottom of the reactor with the conductive sides facing down, a network nanostructure of $3 \mathrm{D} \mathrm{TiO}_{2}$ nanorods can be synthesized as figure s1 shown. The morphological and structural properties of $1 \mathrm{D} / 3 \mathrm{D}$ nanorods are further characterized by TEM analysis. Figure $1 \mathrm{e}$ shows a single flower made of several nanorod petals. The close
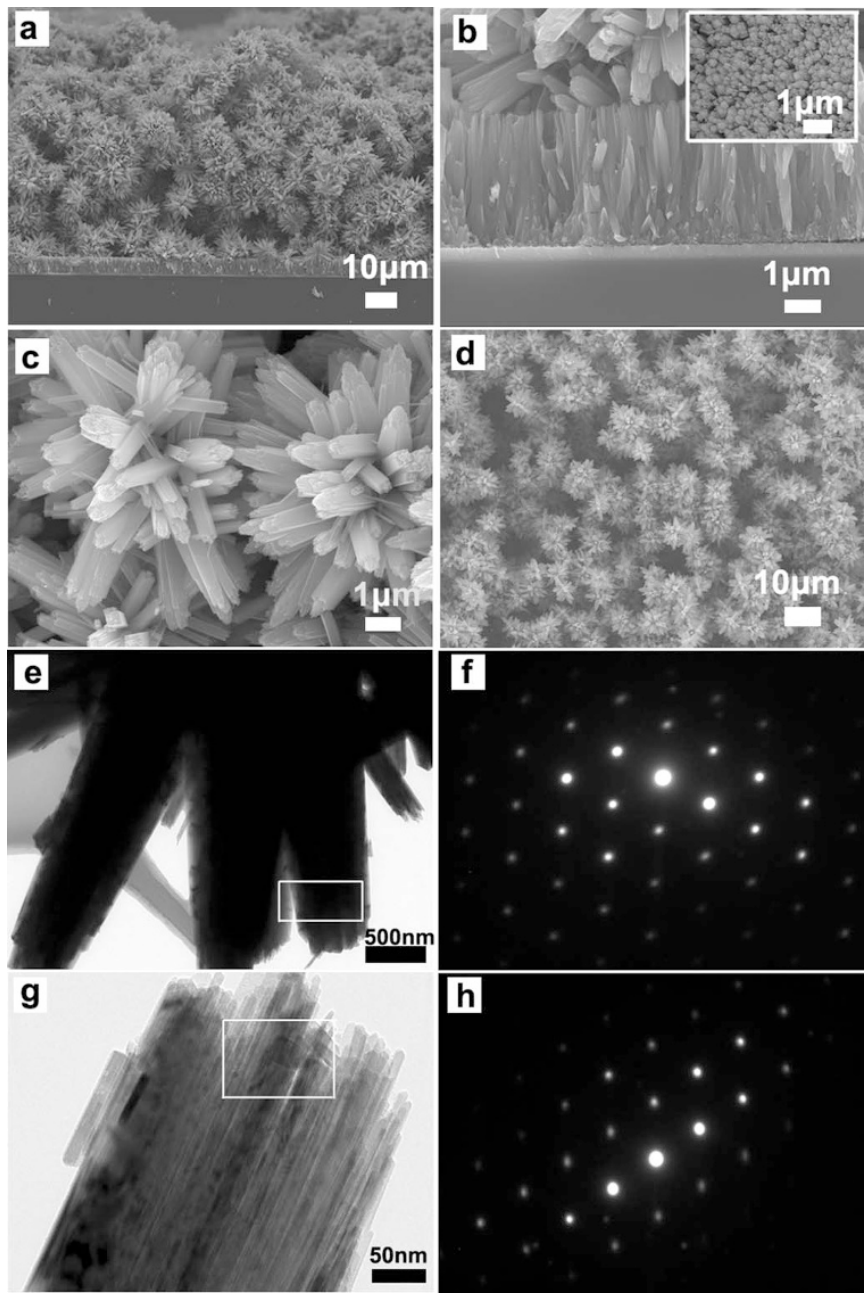

Figure 1| The cross-sectional (a) and plan (c, d) SEM images of 1D/3D $\mathrm{TiO}_{2}$ nanorods, image (b) and the inset image of (b) correspond to the cross-sectional and top view of the bottom layer of $1 \mathrm{D} \mathrm{TiO}_{2}$ nanorod arrays. TEM (e) and SAED (f) characterization of the 3D nanorods; TEM image (g) and SAED image $(\mathrm{h})$ of the bottom layer 1D nanorods.

image (figure $1 \mathrm{~g}$ ) of the single nanorod in bottom layer reveals that the top of nanorod was consisted of a lot of parallel ultrathin nanoneedles. Selected area electron diffraction patterns (SAED) for 3D nanorods (Figure 1f) and 1D nanorods (figure 1h) exhibit that these nanorods have a single crystalline structure. The single-crystal characteristics of the nanorods are very crucial in DSC application, since they will provide fast electronic pathway through the nanorod with few boundary. Moreover, compared to the poor crystallization, the single crystal nanorods exhibited fewer surface defects trapping, it may be result in the lower electron recombination.

The as-prepared $\mathrm{TiO}_{2}$ network structures including $1 \mathrm{D} / 3 \mathrm{D}$ nanorods and $3 \mathrm{D}$ nanorods were etched in a solution containing $5 \mathrm{ml}$ deionized water and $11 \mathrm{ml}$ concentrated hydrochloric acid at $150^{\circ} \mathrm{C}$ for 12 hours. Figure 2 shows detailed SEM images of the etched film. Image (a), (b), (c), and (d) are the morphology of the 3D nanorods sample after etching post-treatment, it can be found that a portion of the $\mathrm{TiO}_{2}$ nanorods in flower-like clusters were hollowed out, forming a structure of nanotubes with the average inner diameter of $150 \mathrm{~nm}$ and the wall thickness of $10 \mathrm{~nm}$. Interestingly, the tip of the tube wall is assembled by some $\mathrm{TiO}_{2}$ nanorods with smaller diameter and the petal of the flower-like cluster have converted into nanotubes. So we denoted the sample as 3D nanotubes in this work. Figure 2 (e) and (g) show the top and cross-sectional image of 1D/3D nanorods samples after acid etching 

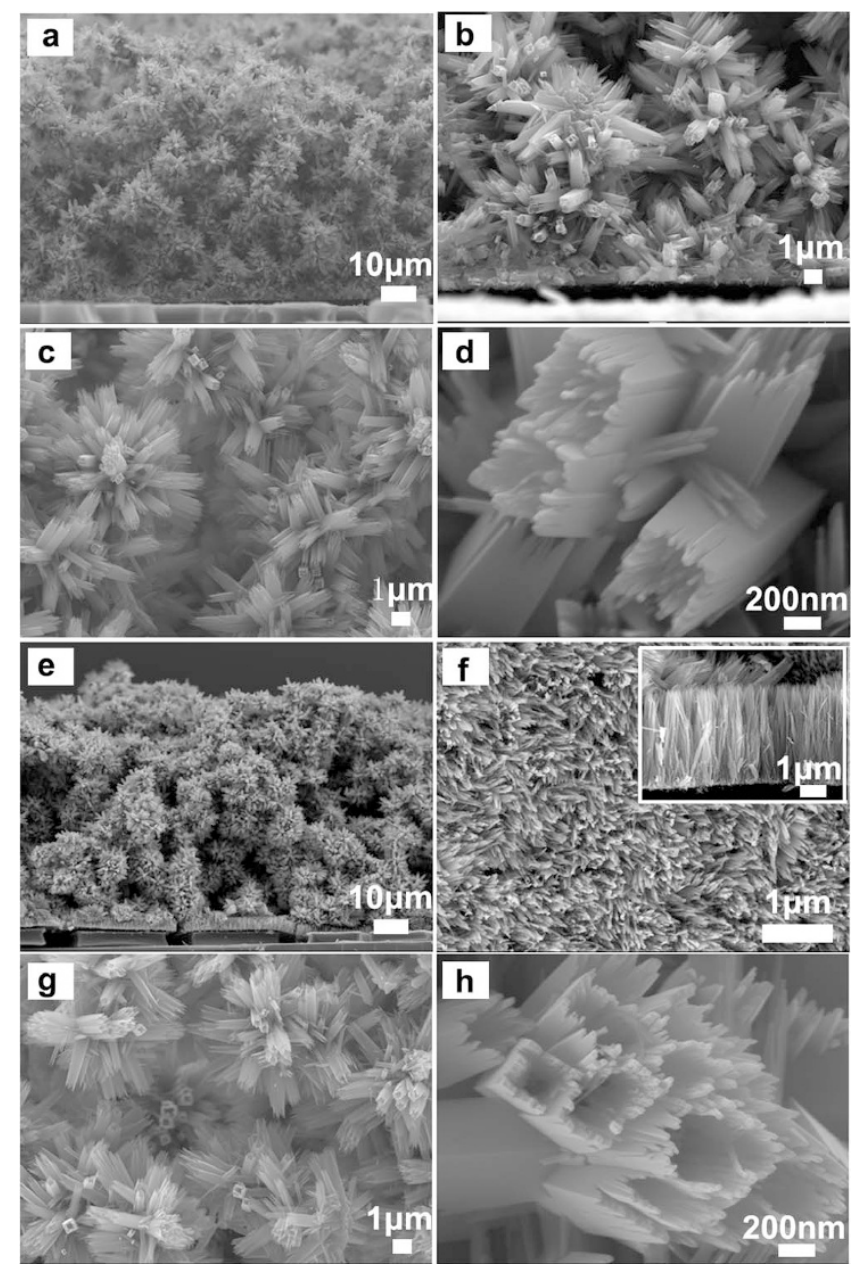

Figure $2 \mid$ FESEM images of the cross-sectional (a, b) and top (c, d) views of $3 \mathrm{D}$ nanotubes. Image (e) and image (g,h) correspond to cross-sectional and top views of $1 \mathrm{D}$ nanorods/3D nanotubes structure, the image (f) and the inset of image (f) are the plan and cross-sectional view of the bottom layer of $1 \mathrm{D} \mathrm{TiO}_{2}$ nanorods.

treatment. As the images shown, the sample maintains bi-layer structure, and the network structure exhibits the same thickness of $70 \mu \mathrm{m}$ as the un-etched one. From the plan (Figure $2 \mathrm{f}$ ) view of the bottom layer of $\mathrm{TiO}_{2}$ nanorod arrays, it can be found that the $\mathrm{TiO}_{2}$ nanorods split into secondary nanorods with a reduced diameter. Obviously, through etching post-treatment, the compactly aligned nanorods arrays were replaced by loosely distributed secondary nanorods with diameter of 12-60 nm, which should be responsible for the enlarged space between the adjacent nanorods. In addition, etching treatment does not change the length of nanorod array significantly. After $12 \mathrm{~h}$ etching treatment, the thickness of $\mathrm{TiO}_{2}$ nanorod arrays is $4 \mu \mathrm{m}$, this is only about $400 \mathrm{~nm}$ thinner than the un-etched one. From the top view of the $1 \mathrm{D} / 3 \mathrm{D} \mathrm{TiO}_{2}$ nanorods after etching at high magnification (figure $2 \mathrm{~h}$ ), the upper layer of 3D nanorods have been hollow, the petal of the flower-like cluster transform from nanorods to nanotubes with an average diameter of $\sim 300 \mathrm{~nm}$ and the wall thickness of $\sim 8 \mathrm{~nm}$, which markedly enlarged the surface area of the sample, and a $1 \mathrm{D}$ nanorods/3D nanotubes structure is formed. The morphological transformation of rutile $\mathrm{TiO}_{2}$ nanorods through etching can be understood as follows:

when the $3 \mathrm{D} \mathrm{TiO}_{2}$ nanorods was immersed in chemical etching solution containing $5 \mathrm{ml}$ DI water and $11 \mathrm{ml}$ concentrated hydrochloric acid for hydrothermal etching, the reaction processes in this system could be illustrated by equation (1)

$$
\mathrm{TiO}_{2}+\mathrm{HCl} \rightarrow \mathrm{TiCl}_{4}+\mathrm{H}_{2} \mathrm{O}
$$

The $3 \mathrm{D} \mathrm{TiO}_{2}$ nanorods begin to dissolve on the relatively unstable crystal faces. The dissolve rate of different crystal faces in rutile $\mathrm{TiO}_{2}$ nanorods follows the sequence $(110)<(100)<(101)<(001)^{20,21}$. Thus, the (001) planes of rutile $\mathrm{TiO}_{2}$ nanorods are the preferential etching planes ${ }^{22}$. Rutile $\mathrm{TiO}_{2}$ nanorods dissolved along the [001] direction, which leads to $\mathrm{TiO}_{2}$ transform from 3D nanorods to 3D nanotubes. Moreover, there are more crystal defects existing in the grain boundaries among $1 \mathrm{D}$ rutile $\mathrm{TiO}_{2}$ nanorod arrays and these sits are favored etching position as well, so that the bottom layer of densely packed $\mathrm{TiO}_{2}$ nanorod arrays split into secondary nanorods with small diameter.

As the SEM images present, we can control the morphology and dimension of $\mathrm{TiO}_{2}$ films by experiment condition. It can be found that the $\mathrm{TiO}_{2}$ films contain only $1 \mathrm{D}$ nanorod arrays while the mount of titanium precursor is less than $0.5 \mathrm{ml}$ as we previously reported $^{16-18}$, and the films present $1 \mathrm{D} / 3 \mathrm{D}$ nanorods network structure as adequate titanium precursor is added. Figure 3 shows the schematic diagram of $\mathrm{TiO}_{2}$ films with different network structures. The structures of $1 \mathrm{D} / 3 \mathrm{D}$ nanorods and $3 \mathrm{D}$ nanorods were successfully synthesized by a single-step hydrothermal route. When the conductive side of FTO glass faces up during the hydrothermal process, a $1 \mathrm{D} / 3 \mathrm{D}$ nanorods structure was obtained, on the contrary, a 3D nanorods structure would be presented when the conductive surface face down. In order to further improve the surface area of the $\mathrm{TiO}_{2}$ films for DSSCs application, the network structure suffered from etching treatment. Finally, the structures of 3D nanorods and 1D/ 3D nanorods were successfully transformed into 3D nanotubes and $1 \mathrm{D}$ nanorods/3D nanotubes through the etching treatment.

The crystallinity of the hydrothermally deposited network structures were examined by X-ray diffraction (XRD) measurement. Figure 4 (a) shows the XRD patterns of the 1D/3D nanorods as prepared, which can be easily indexed to the tetragonal rutile structure of $\mathrm{TiO}_{2}$ (JCPDS No.89-4920), indicating that a crystalline structure has been directly synthesized without annealing treatment. Figure 4 (a), (c) and (d) show the XRD patterns of $\mathrm{TiO}_{2} 1 \mathrm{D} / 3 \mathrm{D}$ nanorods, $3 \mathrm{D}$ nanotubes and $1 \mathrm{D}$ nanorods/3D nanotubes samples respectively. The three curves exhibited the same diffraction peaks locations which match well with the pure rutile phase. All of the four samples present rutile $\mathrm{TiO}_{2}$ single crystals, where the growth direction is along [001] orientation, side surfaces exhibit $\{110\}$ facets, and no additional phases were observed. It is known that the crystalline rutile phase can be advantageous for reducing the electron transport resistance and thus the electron-recombination rate in the photoanode of DSSCs ${ }^{23}$. In addition, compared the XRD patterns of un-etched sample with that of the etched one, it can be found that they possessed the same diffraction peaks regardless of difference in intensity, indicating etching treatment does not destroy the singlecrystalline rutile properties of $\mathrm{TiO}_{2}$ nanorods.

Three kinds of network structures including 1D/3D nanorods (sample I), 3D nanotubes (sample II), and 1D nanorods/3D nanotubes (sample III) are further used as photoanodes in DSSCs. Figure 5 shows typical current density versus voltage (J-V) curves of the three network structure bases DSSCs irradiated by AM 1.5 G simulated sunlight $\left(100 \mathrm{~mW} \mathrm{~cm}^{-2}\right)$, and the detailed photovoltaic parameters are listed in table 1 . As shown in figure 5 and table 1, the open-circuit photovoltage $\left(\mathrm{V}_{\mathrm{oc}}\right)$ of the DSSCs based on the three films have no significant variations. DSSCs with sample I exhibited a relatively low short-circuit current density $\left(\mathrm{J}_{\mathrm{sc}}\right)$ of $5.96 \mathrm{~mA} / \mathrm{cm}^{2}$, an $\mathrm{V}_{\mathrm{oc}}$ of $0.76 \mathrm{~V}$, and a fill factor (FF) of $62 \%$, which gives an overall light-to-electricity conversion efficiency of $2.80 \%$. The cells based on sample II and III present a significant enhancement in the $\mathrm{J}_{\mathrm{sc}}$ values comparison with sample I, which reach 7.68 and $13.40 \mathrm{~mA} / \mathrm{cm}^{2}$, respectively. The cross-sectional SEM images of the three samples (Figure 1a, 


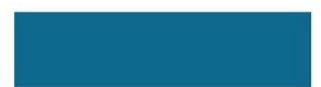

FTO

\section{hydrothermal sythesis the conductive face down}

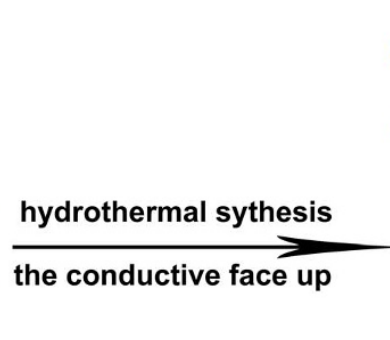

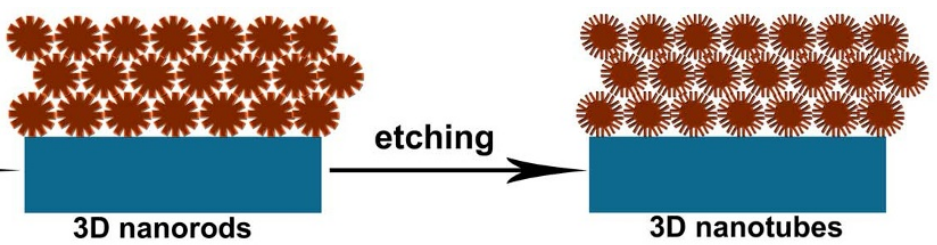

3D nanotubes

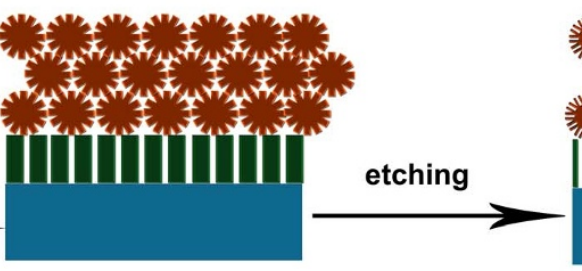

1D/3D nanorods

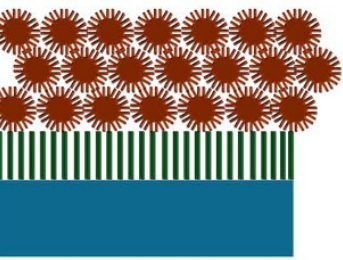

1D nanorods/3D nanotubes

Figure $3 \mid$ A schematic diagram of $\mathrm{TiO}_{2}$ films with different network structures.

Figure $2 \mathrm{a}$ and Figure 2e) clearly show that they have similar thicknesses of $72 \mu \mathrm{m}$, so the effect of the thickness on photovoltaic performance can be ignored. The differences of photovoltaic properties are mainly attributed to increased dye loading due to the larger surface area after the etching post-treatment. It is worth noting that the $\mathrm{J}_{\mathrm{sc}}$ of sample III is $\sim 2.3$ times higher than that of the un-etched one, and a most efficient photovoltaic performance of $6.43 \%$ is achieved for $1 \mathrm{D}$ nanorods/3D nanotubes cells without any further post-treatment of $\mathrm{TiCl}_{4}$, which has frequently been used in a previous report to further improve the performance of DSSCs ${ }^{24,25}$. Comparing the sample II with sample III, it can be found that the $\mathrm{J}_{\mathrm{sc}}$ increases from $7.67 \mathrm{~mA} / \mathrm{cm}^{2}$ to $13.40 \mathrm{~mA} / \mathrm{cm}^{2}$, the enhanced $\mathrm{J}_{\mathrm{sc}}$ may ascribed to the bottom layer of $1 \mathrm{D} \mathrm{TiO}_{2}$ nanorod arrays in sample III, which can provide a direct current pathway for electrons to the external circuit with few grain boundaries. As a result, the power conversion efficiency varies from $3.57 \%$ for sample II, to $6.43 \%$ for sample III.

To obtain better insight into the factors contributing to efficiency, the specific surface area and pore volume of $\mathrm{TiO}_{2}$ photoanode with different network structures were measured by Brunauer-EmmettTeller (BET) and Barrett-Joyner-Halenda (BJH) analysis using a nitrogen adsorption-desorption apparatus. The measured specific surface areas of the three sample were $75.53 \mathrm{~m}^{2} \mathrm{~g}^{-1}, 103.42 \mathrm{~m}^{2} \mathrm{~g}^{-1}$, $134.06 \mathrm{~m}^{2} \mathrm{~g}^{-1}$, respectively. This BET result is in accordance with the SEM image in Fig 1 and Fig 2. The two etching samples showed a

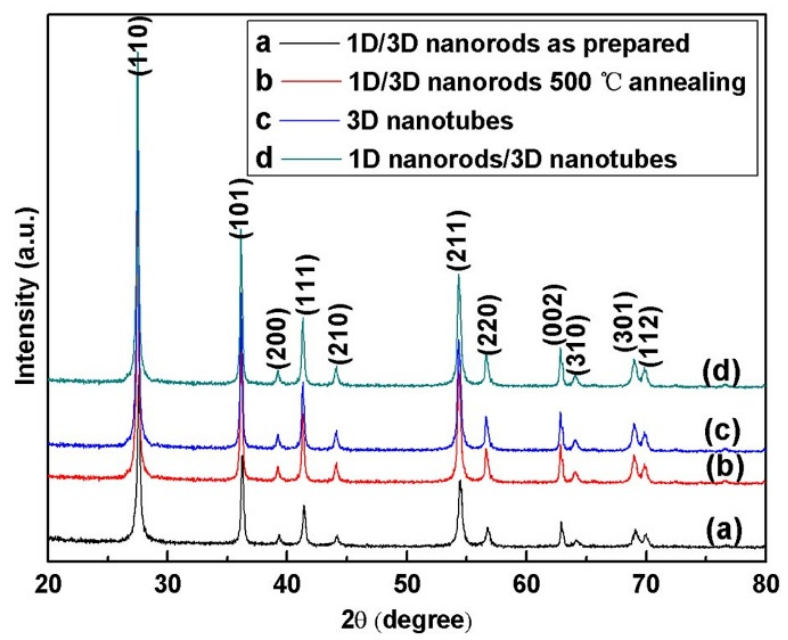

Figure $4 \mid \mathrm{X}$-ray diffraction patterns of these synthesized network structures involving 1D/3D nanorods as prepared (a) 1D/3D nanorods annealing at $500^{\circ} \mathrm{C}$ (b) $3 \mathrm{D}$ nanotubes (c) $1 \mathrm{D}$ nanorods $/ 3 \mathrm{D}$ nanotubes (d). larger surface area than that of the unetching sample. This indicates that the etching samples should provide larger sensitizer surface coverages than the unetching photoelectrodes. The amounts of dyes adsorbed on the three samples were measured by the UV-vis absorption spectra of the N719 dye-desorption solution, which were prepared by immersing the sensitized electrodes into a $0.1 \mathrm{M} \mathrm{NaOH}$ in a mixed solvent (water: ethanol $=1: 1$ ). The amount of dye adsorbed was determined by the molar extinction coefficient of $1.41 \times$ $10^{4} \mathrm{dm}^{3} \mathrm{~mol}^{-1} \mathrm{~cm}^{-1}$ at $515 \mathrm{~nm}^{26}$. It is found that the two etched samples exhibit higher dye-loading capacity than the un-etched film. Especially for 1D nanorods/3D nanotubes sample, it has the largest amount of dye adsorption $\left(236.16 \mathrm{nmol} / \mathrm{cm}^{2}\right)$ and is about 3.6 times larger than that of the un-etched $1 \mathrm{D} / 3 \mathrm{D}$ nanorods films $\left(65.97 \mathrm{nmol} / \mathrm{cm}^{2}\right)$, which result from the enlarged internal surface area via etching treatment, definitely contribute to the enhanced photocurrent density and thus higher DSSC efficiencies. This is well in agreement with $\mathrm{J}-\mathrm{V}$ data.

In order to better understand the different photovoltaic performances of the three DSSCs, the UV/Vis reflectance spectra were further characterized and shown in figure 6 (a). The light-scattering ability of the photoanode is crucial for efficient harvesting of the incident light, the sample with inferior light-scattering ability have a better chance to capture incident light. As the figure 6 (a) shown, the reflectance of the $1 \mathrm{D}$ nanorods/3D nanotubes film (sample III) is

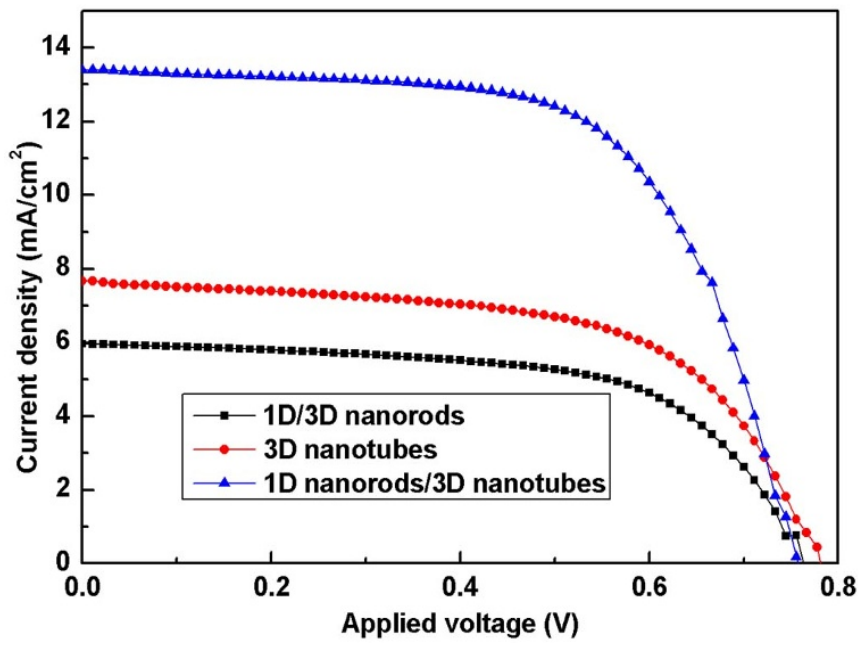

Figure $5 \mid$ The photocurrent-Voltage curve of the DSSCs based on $\mathrm{TiO}_{2}$ photoanode with different network structures (1D/3D nanorods, 3D nanotubes, 1D nanorods/3D nanotubes) measured under AM $1.5 \mathrm{G}$ solar irradiation of $100 \mathrm{~mW} / \mathrm{cm}^{2}$. 
Table 1 | Detail photovoltaic parameters of the DSSCs based on $\mathrm{TiO}_{2}$ photoanode with different network structures (1D/3D nanorods, 3D nanotubes, ID nanorods/3D nanotubes) under illumination of simulated solar light (100 mW/ $\left.\mathrm{cm}^{2}, A M 1.5 \mathrm{G}\right)$

\begin{tabular}{lccccc} 
Sample & $\mathrm{V}_{\mathrm{oc}}(\mathrm{V})$ & $\mathrm{J}_{\mathrm{sc}}\left(\mathrm{mA} / \mathrm{cm}^{2}\right)$ & $\eta(\%)$ & $\mathrm{FF}$ & Dye-loading $\left(\mathrm{nmol} / \mathrm{cm}^{2}\right)$ \\
\hline ID/3D nanorods & 0.76 & 5.96 & 2.80 & 0.62 & 65.97 \\
3D nanotubes & 0.78 & 7.67 & 3.57 & 0.60 & 138.3 \\
1D nanorods/3D nanotubes & 0.76 & 13.40 & 6.43 & 0.63 & 236.16 \\
\hline
\end{tabular}

about $85 \%$ in the range of $400-900 \mathrm{~nm}$, which is higher than the other two films. It is worth noting that sample III and sample II, with etching treatment, shows higher diffuse reflection capabilities in the visible and near infrared regions compared to that of un-etched one (sample I), suggesting that the incident light was significantly scattered within film III and II, which can maximize the use of solar light to improve the light harvesting efficiency, and definitely result in a higher photocurrent for DSSCs based on sample III and II. In addition, the reflectance of the $3 \mathrm{D}$ nanotubes (sample II) is about $70 \%$ in the range of $400-800 \mathrm{~nm}$, it presents a little lower than that of sample III which fabricated by an aligned bottom layer of $1 \mathrm{D}$ nanorod arrays with better light-scattering capacity. The absorption spectra of the three $\mathrm{TiO}_{2}$ network structure photoanodes sensitized with N719 dye have been shown in figure 6 (b). It is found that the dye-sensitized 1D nanorods/3D nanotubes film have best light-harvesting capabilities
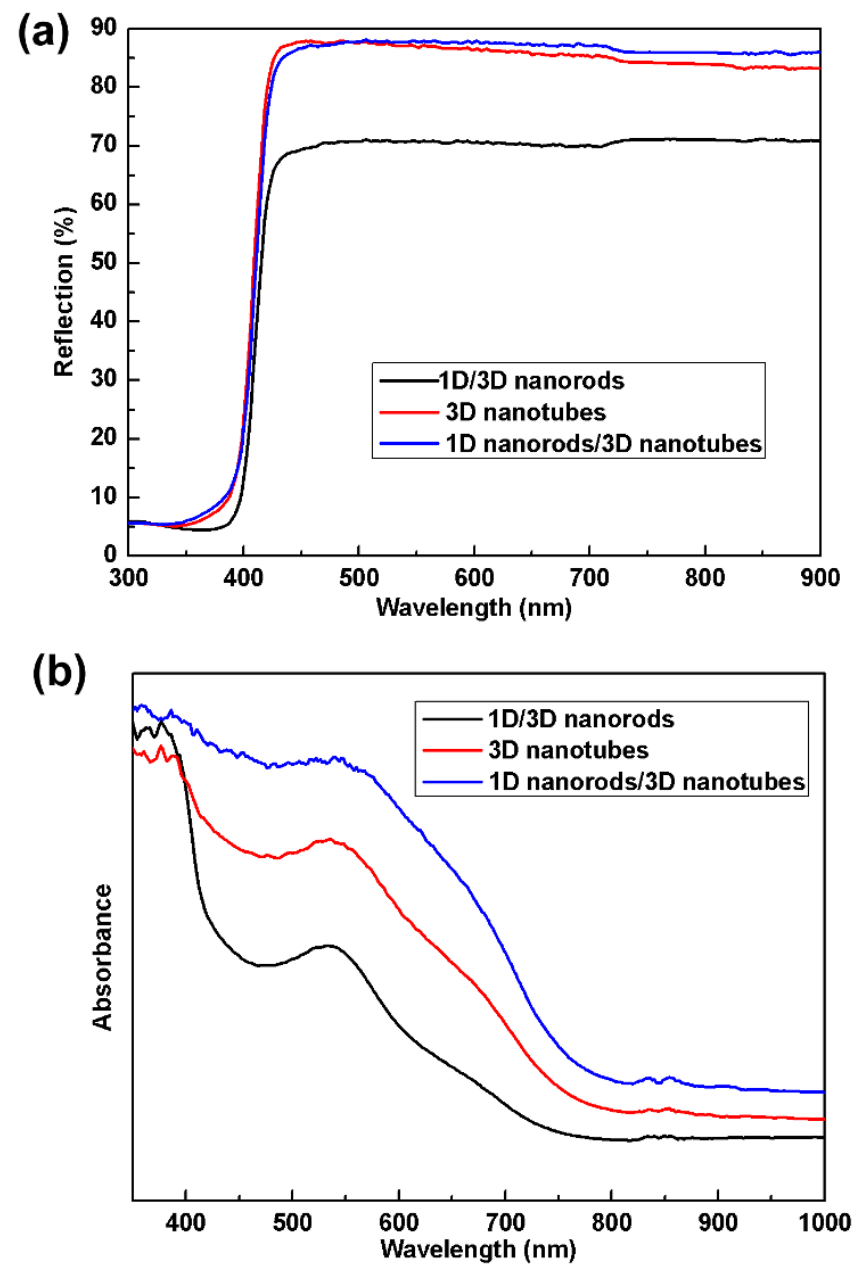

Figure $6 \mid$ (a) Diffused reflectance spectra of different network structures films before dye adsorption without electrolyte and illuminated from the $\mathrm{TiO}_{2}$ side with integrating sphere. (b) UV-Vis absorbance spectra of dyesensitized photoanode with different network structures (1D/3D nanorods, 3D nanotubes, 1D nanorods/3D nanotubes). in the range from $400-700 \mathrm{~nm}$ and the peaks around $530 \mathrm{~nm}$ are the characteristic absorption of the N719 dye. It reveals that the etched films show much higher light absorption, especially during the visible and near infrared regions compared to that without any etching treatment, which is consistent with result of the amount of dye molecules measurement in which etching sample showed the higher dye-loading.

The incident-photo-to-current efficiency (IPCE) spectra could provide further evidence on the light-harvesting efficiency of the DSSCs. Figure 7 displays the IPCE spectra as a function of wavelength from 400 to $800 \mathrm{~nm}$ for those three cells. As can be seen, the IPCE curves of the three cells exhibit similar spectrum shape, and get a maximum efficiency at $530 \mathrm{~nm}$ corresponding to the absorption peak of the N719 dye. The data of IPCE have an order of sample I $<$ sample II $<$ sample III at the visible light wavelength range, which is consistent with $\mathrm{J}_{\mathrm{sc}}$ order. The DSSCs fabricated from 1D nanorods/ $3 \mathrm{D}$ nanotubes photoanode displays the highest IPCE value over a wide range from $400-700 \mathrm{~nm}$ among these three cells. Moreover, the IPCE of the etching sample III increased from $58 \%$ to $90 \%$ around $530 \mathrm{~nm}$ compared to the un-etching sample I. The higher IPCE of cell sample III over a wide range contribute to the increase in efficiency of light harvesting (larger dye molecular loading and higher light reflectance), which could lead to a higher short-circuit current density. In addition, it can be found that the IPCE data of cell sample III shows an obvious red-shift to a longer wavelength compared to the cell sample I and II due to the better light-scattering ability.

Transient photoconductivity and recombination kinetics of $\mathrm{TiO}_{2}$ based cells were studied by OCVD measurements. As is well known electron presents three kinds of motion status at different voltage dependent regions: (1) the high voltage region is corresponding to free electron; (2) the exponential increase region relates to internal trapping of the photoanode material; (3) the inverted parabola at low photovoltage reflects the density of the acceptor in electrolyte. Obviously, the main research object is the middle voltage dependent region which reveals the electron recombination process in the anode

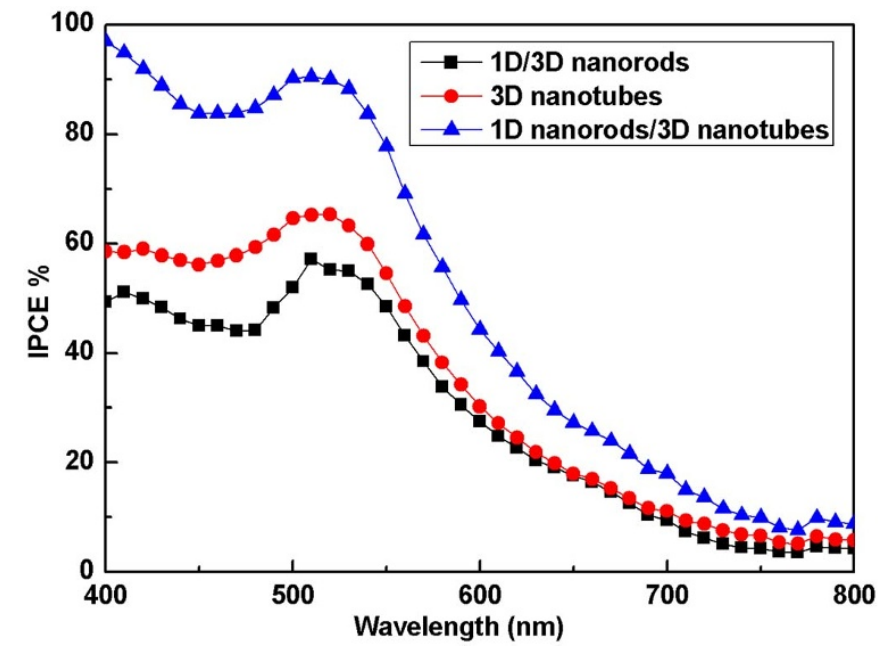

Figure $7 \mid$ Incident photon to current conversion efficiency (IPCE) curves of DSSCs based on $\mathrm{TiO}_{2}$ photoanodes with different network structures. 
and the electron lifetime. We carried out the experiment according to the technique reported by Zaban et $\mathrm{al}^{27,28}$. For the photoinduced OCVD measurements, the cell was irradiated with AM 1.5 solar light for $10 \mathrm{~s}$ to a steady voltage, then the illumination was turned off using a shutter, the OCVD was recorded with an electrochemical work station, typically the measurement interval was $10-50 \mathrm{~ms}$. The response time is obtained by the reciprocal of the derivative of the decay curve normalized by the thermal voltage as equation (2)

$$
\tau_{n}=\frac{-K_{B} T}{e}\left[\frac{d V_{o c}}{d t}\right]^{-1}
$$

Where $K_{B}$ is the Boltzmann constant taken to be $1.38 \times 10^{-23} \mathrm{~J} / \mathrm{K}, \mathrm{T}$ is the temperature, $\mathrm{K}_{\mathrm{B}} \mathrm{T}$ gives the thermal energy, $\mathrm{e}$ is the positive elementary charge to be $1.69 \times 10^{-19} \mathrm{C}$ and $\mathrm{dV}_{\text {oc }} / \mathrm{dt}$ is the derivative of the open circuit voltage transient. The data shown in figure 8 (a) consist of three OCVD curves based on different network structures $\mathrm{TiO}_{2}$ photoanodes. For a linearly with time, the curves indicate a supralinear decay where the lifetime recedes to larger values. Figure 8 (b) shows the lifetime values obtained from figure 8 (a) using equation (2). It can be seen from figure 8 (b) that the lifetimes of DSSCs based on sample III are longer than that of sample II at the voltage range of $0.4 \mathrm{~V}-0.7 \mathrm{~V}$, which may be due to the bottom layer of $1 \mathrm{D}$ nanorods arrays that provide the electron pathway with few boundary. It is worth noting that the two etched samples exhibit superior characteristics with longer lifetime than the un-etched film, indicating fewer recombination centers in the etched sample. The grain boundaries among rutile $\mathrm{TiO}_{2}$ nanorods are favored etching positions, owing to their higher concentration of defects. So the etchingtreatment reduces the defects of samples, which suppress the recombination pathway at the electrode-electrode and electrode-electrolyte interface.

Electrochemical impedance spectroscopy (EIS) is a powerful tool to clarify the transport resistance in DSSCs. Figure 9 shows the electrochemical impedance spectra of the above different DSSCs at the open circuit voltage illuminated with AM 1.5 solar light of $100 \mathrm{~mW} \mathrm{~cm} \mathrm{~cm}^{-2}$ and a frequence range from $0.1 \mathrm{HZ}$ to $10^{5} \mathrm{~Hz}$. Generally, the first gap $\left(R_{s}\right)$ is related to the sheet resistance on the transparent conductive oxide (TCO) substrates and the contact resistance between $\mathrm{TCO}$ and $\mathrm{TiO}_{2}$. In addition, three semicircles can be observed from the impedance spectra, the semicircle in high frequency region represents the charge transfer resistance at the electrolyte/Pt-electrode interface $\left(\mathrm{R}_{\mathrm{pt}}\right)$, the second semicircles are assigned to electron transfer at the interface between the $\mathrm{TiO}_{2} /$ dye/ electrolyte $\left(R_{c t}\right)$, and the third semicircle observed in the low frequency region correspond to the characteristics of diffusion of the $\mathrm{I}^{-}$/ $\mathrm{I}^{3-}$ redox electrolytes electron ${ }^{9,29}$. As shown in table 2, the three DSSCs show similar values of $R_{s}$ and $R_{p t}$, which ascribes to the use of the same electrolyte and counter electrodes. However, the charge transfer resistance $R_{c t}$ of two etched samples is obviously smaller than that of unetched samples, hence denoting the more superior charge transport characteristics after etching treatment. It is worth mentioning that the smaller value of $\mathrm{R}_{\mathrm{ct}}$ is observed from sample III, as compared to the sample II, this indicated that the addition of $\mathrm{TiO}_{2}$ nanorod arrays contributes to the reduction of charge transfer resistance, which leading to an increase of the $\mathrm{J}_{\mathrm{sc}}{ }^{30,31}$.

The performance of the DSSCs can be improved through many ways. One well-known method is post-treatment the $\mathrm{TiO}_{2}$ photoanode with titanium tetrachloride $\left(\mathrm{TiCl}_{4}\right)$ solution. The $\mathrm{TiCl}_{4}$ treatment can results in an improvement of $10-30 \%$ in photocurrent. It is claimed that the treatment by $\mathrm{TiCl}_{4}$ could introduce $3-10 \mathrm{~nm}$ nanoparticles onto $\mathrm{TiO}_{2}$ photoanode to increase the surface area. Accordingly, it improves the dye-loading capacity of the photoanode. In addition, the $\mathrm{TiCl}_{4}$ surface treatment can improve the electron transport and light scattering. In this work, the as-prepared $\mathrm{TiO}_{2} 1 \mathrm{D}$ nanorods/3D nanotubes sample was immersed in $0.2 \mathrm{M}$ $\mathrm{TiCl}_{4}$ aqueous solution at room temperature for $48 \mathrm{~h}$, and then was (a)

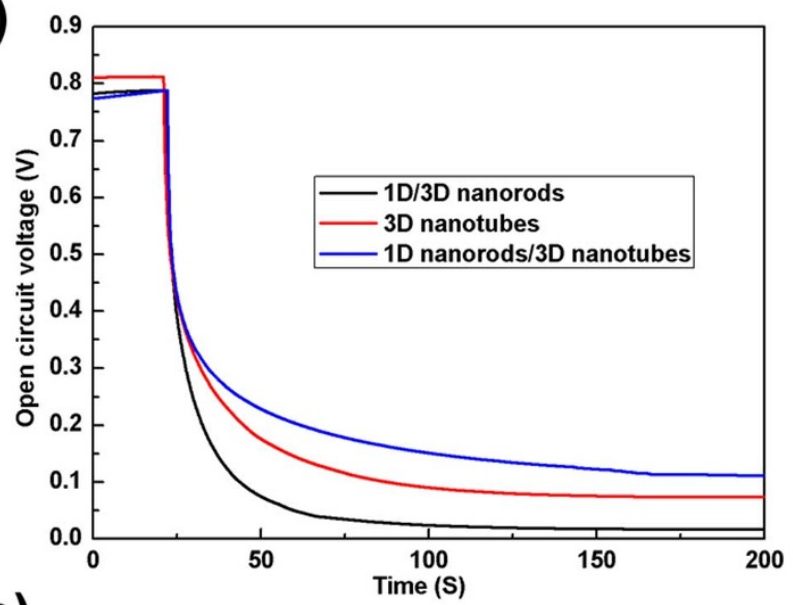

(b)

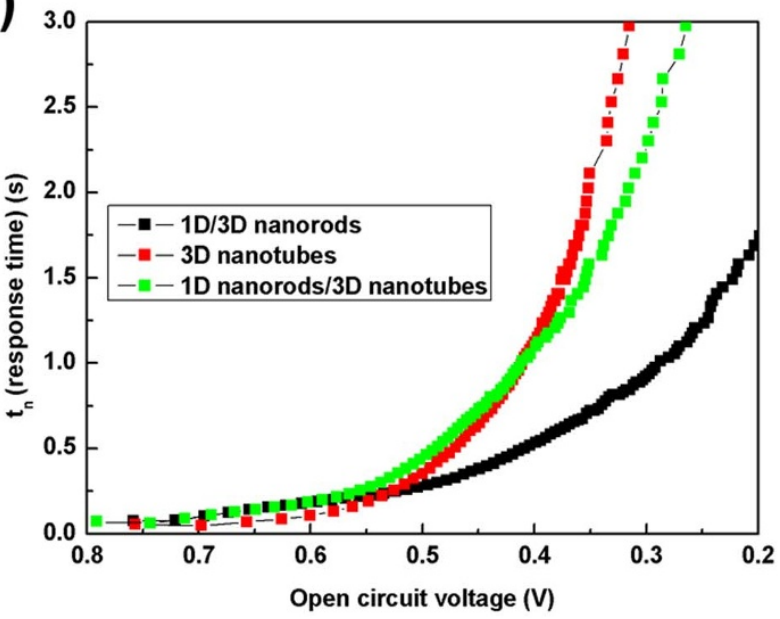

Figure 8 $\mid$ (a) Open-circuit voltage decay measurement of the DSSCs based on $\mathrm{TiO}_{2}$ photoanode with different network structures, (b) The electron lifetime derived from equation (2) as a function of $\mathrm{V}_{\mathrm{oc}}$.

annealed in air at $450^{\circ} \mathrm{C}$ for $30 \mathrm{~min}$. FE-SEM images of the modified sample are shown in Figure $10(a, b, c)$. As the plan-views shown, the sample maintains the flower cluster structures which composed of a

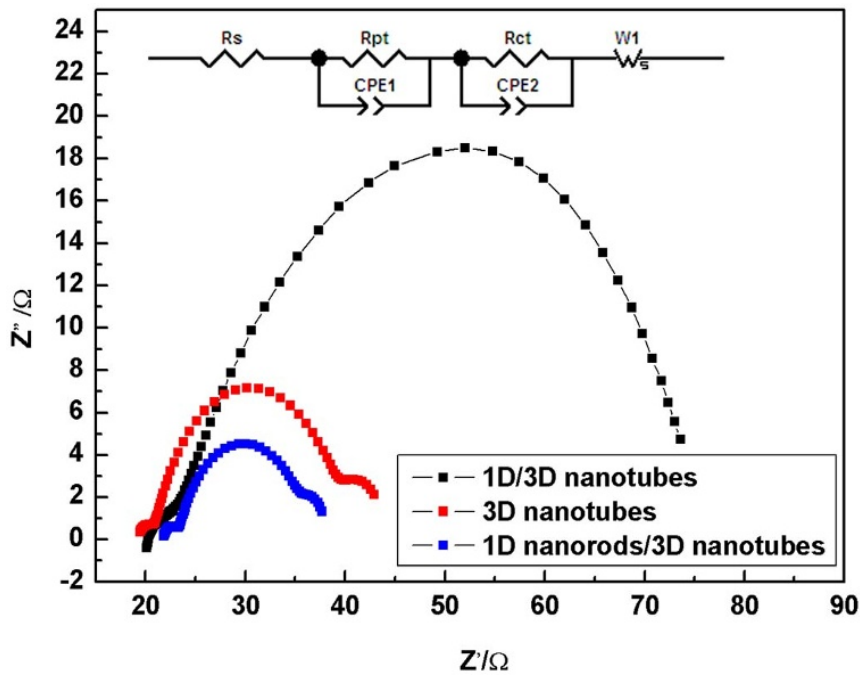

Figure 9 EIS of the DSSCs based on $\mathrm{TiO}_{2}$ photoanode with different network structures at the open circuit voltage illuminated with AM 1.5 solar light of $100 \mathrm{~mW} \mathrm{~cm}^{-2}$. The equivalent circuit used to fit the experimental data is shown as an inset. 
Table 2 | Series resistance (Rs), charge transfer resistance (Rpt), and electron transfer and recombination (Rct) of the DSSCs fabricated using different photoanodes

\begin{tabular}{|c|c|c|c|}
\hline Sample & $\mathrm{Rs} / \Omega$ & $\mathrm{Rpt} / \Omega$ & $\mathrm{Rct} / \Omega$ \\
\hline $\begin{array}{l}\text { 1D/3D nanorods } \\
\text { 3D nanotubes } \\
\text { 1D nanorods /3D nanotubes }\end{array}$ & $\begin{array}{l}20.18 \\
21.75 \\
19.21\end{array}$ & $\begin{array}{l}1.434 \\
1.524 \\
1.738\end{array}$ & $\begin{array}{l}26.73 \\
12.48 \\
4.874\end{array}$ \\
\hline
\end{tabular}

large number of nanotubes, the inside and outside surface of the nanotubes are covered with a mass of $\mathrm{TiO}_{2}$ nanoparticles and the surfaces become rough. From the top view at high magnification (Figure 10c), the diameter of nanoparticle is about $10-20 \mathrm{~nm}$. Figure 10 (c) gives the cross-sectional image of $\mathrm{TiO}_{2} 1 \mathrm{D}$ nanorod arrays at the bottom layer, which shows a lot of $\mathrm{TiO}_{2}$ nanoparticles also attach on surface of the nanorod arrays. Figure $10(\mathrm{~d})$ presents the J-V curves and photovoltaic parameters of DSSCs based on the $\mathrm{TiCl}_{4}$ modified 1D nanorods/3D nanotubes photoanode. After the $\mathrm{TiCl}_{4}$ treatment at room temperature for $48 \mathrm{~h}$, the cell attained an over efficiency of $7.68 \%$ with $\mathrm{J}_{\mathrm{sc}}$ of $18.3 \mathrm{~mA} / \mathrm{cm}^{2}, \mathrm{~V}_{\mathrm{oc}}$ of $0.72 \mathrm{~V}$, and an FF of $58.29 \%$, the $\mathrm{J}_{\mathrm{sc}}$ and conversion efficiency of the cell were increased through the $\mathrm{TiCl}_{4}$ treatment by $36 \%$ and $20 \%$, respectively, whereas the $\mathrm{V}_{\text {oc }}$ and FF decreased a little after the $\mathrm{TiCl}_{4}$ treatment, this result suggests that the increase in the solar cell performance was mostly derived from the increase in current density. The large increase of $\mathrm{J}_{\mathrm{sc}}$ can be explained as follows. After $\mathrm{TiCl}_{4}$ post-treatment, a dense amorphous $\mathrm{TiO}_{2}$ particles forming on the surface of bare anotubes or nanorods will facilitate electron transfer and increase the surface area for more light capture. The procedure leads to increased dye adsorption due to increased roughness. A thin blocking layer of $\mathrm{TiO}_{2}$ is deposited on the naked FTO surface that reduces the recombination loss between accumulated electrons and electrolyte ${ }^{32,33}$. All these factors help to achieve higher energy conversion efficiency after $\mathrm{TiCl}_{4}$ treatment.

In conclusion, $\mathrm{TiO}_{2} 1 \mathrm{D} / 3 \mathrm{D}$ nanorods network structure are grown directly on transparent conductive fluorine-doped tin oxide substrates by a single-step hydrothermal route. Followed by a secondary hydrothermal etching treatment, the bottom layer of $\mathrm{TiO}_{2}$ nanorod arrays split into secondary nanorods with a reduced diameter, and the up layer of 3D nanorods have been hollow, which markedly enlarge the surface area of the sample, and a $1 \mathrm{D}$ nanorods/3D nanotubes bi-layer structure is formed. The $1 \mathrm{D}$ nanorods/3D nanotubes sample are further applied as the photoanodes in dye sensitized solar cells (DSSCs). Compared to a 1D/3D nanorods based cell, the photovoltaic performance of the $1 \mathrm{D}$ nanorods $/ 3 \mathrm{D}$ nanotubes $\mathrm{TiO}_{2}$ cell (a)

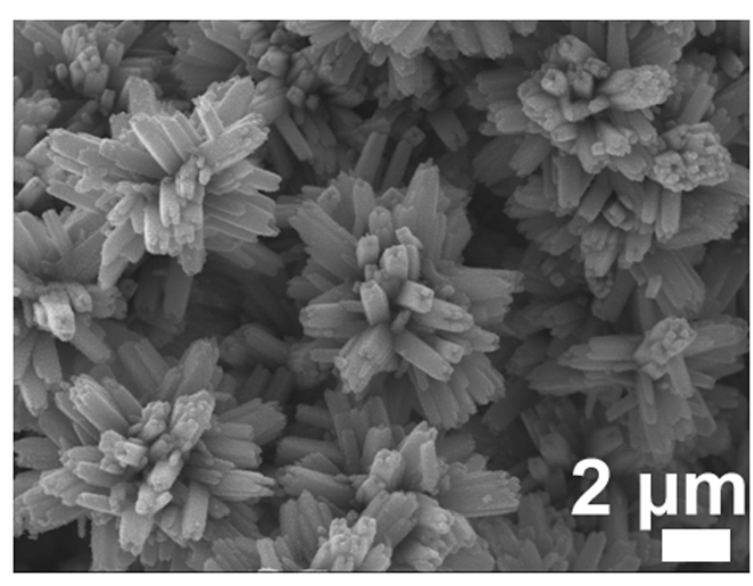

(c)

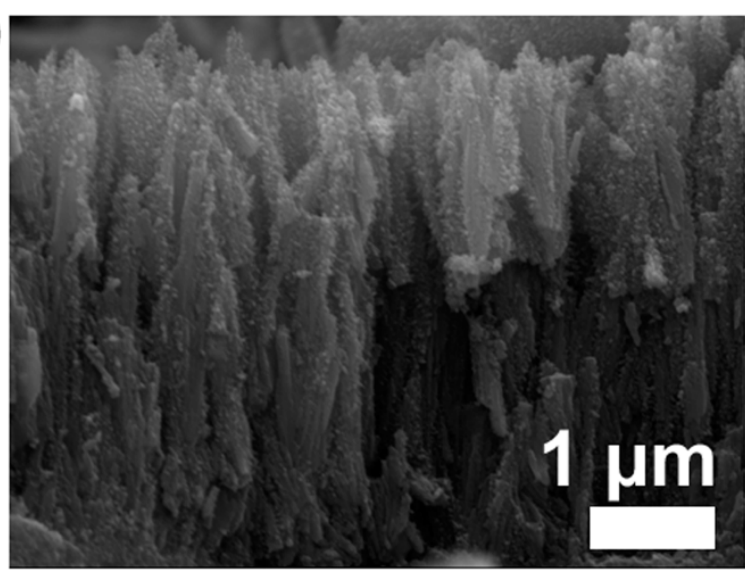

(b)

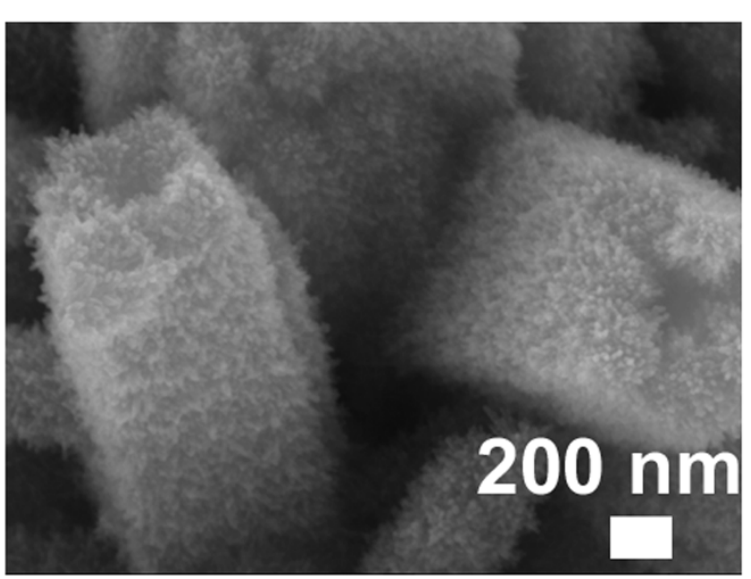

(d)

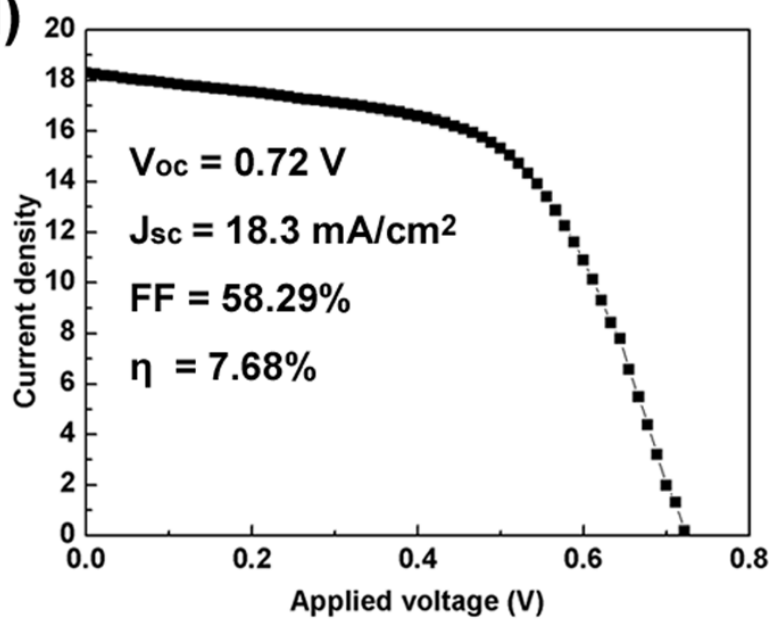

Figure 10 $\mid$ The plan (a) and cross sectional (c) SEM images of 1D nanorods/3D nanotubes photoanode modified with $\mathrm{TiCl}_{4}$ treatment, image (b) correspond to the top view of the $\mathrm{TiCl}_{4}$ modified sample at high magnification. Image (d) presents the J-V curves and photovoltaic parameters of DSSCs based on the $\mathrm{TiCl}_{4}$ modified 1D nanorods/3D nanotubes photoanode. 
exhibits excellent DSSC performance, which results from the large dye-loading, the superior light scattering, rapid electron transport and lower electron recombination rate. The DSSCs based on 1D nanorods/3D nanotubes exhibits a high power conversion efficiency of $7.68 \%$ with $\mathrm{TiCl}_{4}$ treatment, which is remarkably higher than that of the $1 \mathrm{D} / 3 \mathrm{D}$ nanorods $(2.80 \%)$ photoelectrode. In order to understand the specific role of $\mathrm{TiO}_{2}$ nanorod arrays in the $1 \mathrm{D}$ nanorods $/ 3 \mathrm{D}$ nanotubes structure, we have compared the photovoltaic performance of $1 \mathrm{D}$ nanorods/3D nanotubes structure with 3D nanotubes photoanode, and the detailed transient properties of these network structure in DSSCs are analyzed by open circuit voltage decay measurements, the $1 \mathrm{D}$ nanorods/3D nanotubes sample exhibits superior characteristics, with longer life time indicating rapider electron transport rate than 3D nanotubes sample, which attributed to the electron pathway provided by $1 \mathrm{D}$ nanorod arrays.

\section{Methods}

Hydrothermal Synthesis of 1D/3D nanorods and 3D nanorods on FTO substrate. The procedure for obtaining $\mathrm{TiO}_{2}$ nanorods network architecture on FTO substrate likes that developed by Liu et al using hydrothermal method ${ }^{34}$. All the chemicals were of analytic grade and used without further purification. Titanium butoxide, concentrated hydrochloric acid ( $\mathrm{HCl}, 36.5 \%-38 \%$ by weight) and deionized water were used as titanium precursor, acidic medium and solvent, respectively. In a typical synthesis, $16 \mathrm{ml}$ of deionized water, $0.9 \mathrm{ml}$ of titanium butoxide and $16 \mathrm{ml}$ hydrochloric acid were mixed in a Teflon-lined autoclave of 50-ml capacity under magnetic stirring. A piece of FTO substrate $\left(2 \times 2 \mathrm{~cm}^{2}\right)$, through an ultrasonically cleaning with acetone, anhydrous alcohol, and deionized water, was lied flat on the bottom of the reactor with the conductive side facing up. Subsequently, the autoclave was sealed and maintained at $150^{\circ} \mathrm{C}$ for $10 \mathrm{~h}$. After cooling the autoclave to room temperature, the $\mathrm{TiO}_{2}$ films were rinsed extensively with deionized water and dried in ambient air and designated as 1D/3D nanorods. For the synthesis of 3D nanorods, the FTO substrate was place in the autoclave as the conductive side facing down.

Preparation of $1 \mathrm{D}$ nanorods/3D nanotubes and 3D nanotubes. The as-prepared rutile $1 \mathrm{D} / 3 \mathrm{D}$ nanorods and $3 \mathrm{D}$ nanorods were immersed into a solution of $5 \mathrm{ml} \mathrm{DI}$ water and $11 \mathrm{ml} \mathrm{HCl}(36.0-38.0 \mathrm{w} \%)$ and hydrothermally treated at $150^{\circ} \mathrm{C}$ for $12 \mathrm{~h}$. After the hydrothermal reaction finished, the sample rinsed extensively with deionized water, and dried in ambient air. The samples were annealed at $500^{\circ} \mathrm{C}$ for $2 \mathrm{~h}$ in the air atmosphere.

Transferring the $\mathrm{TiO}_{2}$ network structure to FTO substrate. After the chemical etching treatment, the $\mathrm{TiO}_{2}$ network structure were separated from the FTO substrate, the detached free standing $\mathrm{TiO}_{2}$ film with network structure were carefully handled with tweezers and subsequently transferred onto a new FTO glass which were coated with a self-prepared ultra-thin adhesive $\mathrm{TiO}_{2}$ paste. For a practical application, the adhesive $\mathrm{TiO}_{2}$ paste is needed to have a good adhesion property. The $\mathrm{TiO}_{2}$ network structure photoanodes were obtained after an annealing process of $500^{\circ} \mathrm{C}$ for $2 \mathrm{~h}$ in the air atmosphere.

Solar cell fabrication. In order to fabricate the DSSC, the calcined $\mathrm{TiO}_{2}$ network structure photoanode was immersed in ethanol solution of $0.03 \mathrm{mM}$ Ruthenium dye (N719) for $24 \mathrm{~h}$. The dye-adsorbed $\mathrm{TiO}_{2}$ photoanode was washed with ethanol to remove the redundant dye molecules without adsorption and dried under nitrogen flow at room temperature. A DSSC was fabricated using a standard two electrode configuration, comprising dye loaded $\mathrm{TiO}_{2}$ network structure as the photoelectrode and platinum coated FTO as the counter electrode. Afterward, the iodide-base electrolyte was used as the redox couple and was injected from the edge of the DSSCs to evaluate their photovoltaic performance.

Characterization. SEM and XRD were utilized to characterize the morphology and structure of the $\mathrm{TiO}_{2}$ nanostructure. The diffuse reflectance spectra and the amount of dye adsorbed on $\mathrm{TiO}_{2}$ nanostructures were measured by UV-3600 spectrophotometer. Photocurrent density-voltage $(\mathrm{J}-\mathrm{V})$ curves of the DSSCs were recorded using a Keithley 2420 digital multimeter under the simulated AM 1.5 illuminations $\left(100 \mathrm{~mW} . \mathrm{cm}^{-2}\right)$ and an active area of $0.16 \mathrm{~cm}^{-2}$ was used. IPCE spectra were recorded with the help of Oriel QE/IPCE Measurement Kit (equipped with 150$300 \mathrm{~W}$ full spectrum solar simulators). OCVD measurements were obtained with $\mathrm{CHI}$ Electrochemical work station (model-CHI-660D). EIS characteristics were carried out using an electrochemical workstation (CHI-660D) with a $10 \mathrm{mV}$ AC signal over the frequency range of $0.1-10^{5} \mathrm{HZ}$ under $100 \mathrm{~mW} \mathrm{~cm}{ }^{-2}$ illumination.

1. O’Regan, B. \& Grätzel, M. A low-cost, high-efficiency solar cell based on dye sensitized colloidal $\mathrm{TiO}_{2}$ films. Nature 353, 737-740 (1991).

2. Grätzel, M. Photoelectrochemical cells. Nature 414, 338-344 (2001)

3. Yum, J. H. et al. Phosphorescent energy relay dye for improved light harvesting response in liquid dye-sensitized solar cells. Energy Environ. Sci. 3, 434-437 (2010).
4. Liu, C. J., Burghaus, U., Besenbacher, F. \& Wang, Z. L. Preparation and characterization of nanomaterials for sustainable energy production. ACS Nano. 4, 5517-5526 (2010).

5. Yu, X. et al. One-step ammonia hydrothermal synthesis of single crystal anatase $\mathrm{TiO}_{2}$ nanowires for highly efficient dye-sensitized solar cells. J. Mater. Chem. A 1, 2110-2117 (2013).

6. Wu, W. Q. et al. Morphology-controlled cactus-like branched anatase $\mathrm{TiO}_{2}$ arrays with high light-harvesting efficiency for dye-sensitized solar cells. J. Power Sources 260, 6-11 (2014).

7. Chu, L. et al. A general method for preparing anatase $\mathrm{TiO}_{2}$ treelike-nanoarrays on various metal wires for fiber dye-sensitized solar cells. Sci. Rep. 4, 4420 (2014).

8. Shao, F., Sun, J., Gao, L., Yang, S. W. \& Luo, J. Q. Forest-like $\mathrm{TiO}_{2}$ hierarchical structures for efficient dye-sensitized solar cells. J. Mater. Chem. 22, 6824-6830 (2012).

9. Roh, D. K., Chi, W. S., Jeon, H., Kim, S. J. \& Kim, J. H. High efficiency solid-state dye-sensitized solar cells assembled with hierarchical anatase pine tree-like $\mathrm{TiO}_{2}$ nanotubes. Adv. Funct. Mater. 24, 379-386 (2014).

10. Mali, S. S. et al. Single-step synthesis of 3D nanostructured $\mathrm{TiO}_{2}$ as a scattering layer for vertically aligned 1D nanorods photoanodes and their dye-sensitized solar cell properties. CrystEngComm. 15, 5660-5667 (2013).

11. $\mathrm{Yu}, \mathrm{H}$. et al. Hydrothermal synthesis of a crystalline rutile $\mathrm{TiO}_{2}$ nanorods based network for efficient dye-sensitized solar cells. Chem. Eur. J. 19, 13569-13574 (2013).

12. Sun, Z. Q., Kim, J. H., Zhao, Y., Attard, D. \& Dou, S. X. Morphology-controllable 1D-3D nanostructured $\mathrm{TiO}_{2}$ bilayer photoanodes for dye-sensitized solar cells. Chem. Commun. 49, 966-968 (2013).

13. Zhu, K., Neale, N. R., Miedaner, A. \& Frank, A. J. Enhanced charge-collection efficiencies and light scattering in dye-sensitized solar cells using oriented $\mathrm{TiO}_{2}$ nanotubes arrays. Nano Lett. 7, 69-74 (2007).

14. Zhang, J. et al. Transfer and assembly of large area $\mathrm{TiO}_{2}$ nanotube arrays onto conductive glass for dye sensitized solar cells. J. Power Sources 247, 807-812 (2014).

15. Kim, D., Ghicov, A., Albu, S. P. \& Schmuki, P. Bamboo-type $\mathrm{TiO}_{2}$ nanotubes: improved conversion efficiency in dye- sensitized solar cells. J. Am. Chem. Soc. 130, 16454-16455 (2008)

16. Wang, B. Y. et al. Power conversion efficiency enhancement of various size CdS quantum dots and dye co-sensitized solar cells. Int. J. Hydrogen Energy. 38, 16733-16739 (2013).

17. Wang, B. Y. et al. Role of $\mathrm{Co}^{2+}$ incorporation in significant photocurrent enhancement of electrochemical deposited CdSe quantum dots sensitized $\mathrm{TiO}_{2}$ nanorods arrays solar cells. Int. J. Electrochem. Sci. 8, 7175-7186 (2013).

18. Hu, Y.X. et al. Synthesis and photoelectrochemical response of CdS quantum dotsensitized $\mathrm{TiO}_{2}$ nanorods array photoelectrodes. Nanoscale Res Lett. 8, 222-226 (2013).

19. Zhao, B. et al. A 3D porous architecture composed of $\mathrm{TiO}_{2}$ nanotubes connected with a carbon nanofiber matrix for fast energy storage. J. Mater. Chem. A 1, 12310-12320 (2013).

20. Kumar, A., Madaria, A. R. \& Zhou, C. W. Growth of aligned single-crystalline rutile nanowires on arbitrary substrates and their application in dye sensitized solar cells. J. Phys. Chem. C. 114, 7787-7792 (2010).

21. Cheng, H. M., Ma, J. M., Zhao, Z. G. \& Qi, L. M. Hydrothermal preparation of uniform nanosize rutile and anatase particles. Chem. Mater. 7, 663-671 (1995).

22. Liu, L. et al. Fabrication of rutile $\mathrm{TiO}_{2}$ tapered nanotubes with rectangular cross sections via anisotropic corrosion route. Chem. Commun. 46, 2402-2404 (2010)

23. Feng, X. J., Zhu, K., Frank, A. J., Grimes, C. A. \& Mallouk, T. E. Rapid charge transport in dye-sensitized solar cells made from vertically aligned single-crystal rutile $\mathrm{TiO}_{2}$ nanowires. Angew. Chem. Int. Ed. 51, 2727-2730 (2012).

24. Wang, S. M. et al. Optimization of single-crystal rutile $\mathrm{TiO}_{2}$ nanorods arrays based dye-sensitized solar cells and their electron transport properties. J. Power Sources 235, 193-201 (2013).

25. Charoensirithavorn, P. et al. Improvement of dye-sensitized solar cell through $\mathrm{TiCl}_{4}$-treaten $\mathrm{TiO}_{2}$ nanotube arrays. J. Electrochem. Soc. 157, B354-356 (2010).

26. Fan, K., Zhang, W., Peng, T. Y., Chen, J. N. \& Yang, F. Application of TiO(2) fusiform nanorods for dye-sensitized solar cells with significantly improved efficiency. J. Phys. Chem. C 115, 17213-17219 (2011).

27. Bisquert, J., Zaban, A., Greenshtein, M. \& Sero, I. M. Determination of rate constants for charge transfer and the distribution of semiconductor and electrolyte electronic energy levels in dye-sensitized solar cells by open-circuit photovoltage decay method. J. Am. Chem. Soc. 126, 13550-13559 (2004).

28. Zaban, A., Greenshtein, M \& Bisquert, J. Determination of the electron lifetime in nanocrystalline dye solar cells by open-circuit voltage decay measurements. ChemPhysChem. 4, 859-864 (2003).

29. Zhao, J. Y., Yao, J. X., Zhang, Y. Z., Guli, M. \& Xiao, L. Effect of thermal treatment on $\mathrm{TiO}_{2}$ nanorod electrodes prepared by the solvothermal method for dyesensitized solar cells: surface reconfiguration and improved electron transport. J. Power Sources 255, 16-23 (2014).

30. Wang, H., Leonard, L. S. \& Hu, Y. H. Promoting effect of grapheme on dyesensitized solar cells. Ind. Eng. Chem. Res. 51, 10613-10620 (2012).

31. Gratzel, M. Dye-sensitized solar cells. J. Photochem. Photobiol., C: Photochem. Rev. 4, 145-153 (2003)

32. Burke, A. et al. The function of a $\mathrm{TiO}_{2}$ compact layer in dye-sensitized solar cells incorporating planar organic dyes. Nano Lett. 8, 971-981 (2008). 
33. Noh, S. I., Bae, K. N., Ahn, H. J. \& Seong, T. Y. Improved efficiency of dye sensitized solar cells through fluorine-doped $\mathrm{TiO}_{2}$ blocking layer. Ceram. Int. 39, 8097-8101 (2013)

34. $\mathrm{Liu}, \mathrm{B}$. \& Aydil, S. Growth of oriented single-crystalline rutile $\mathrm{TiO}_{2}$ nanorods on transparent conducting substrates for dye-sensitized solar cells. J. Am. Chem. Soc. 131, 3985-3990 (2009).

\section{Acknowledgments}

This work is supported in part by the National Natural Science Foundation of China (Nos. 51372075, 51311130312), Research Fund for the Doctoral Program of Higher Education of China (RFDP, No.20124208110006).

\section{Author contributions}

W.H. contributed to establishing the scientific principles of the 3D network DSSCs. supervising the work, analyzing the data, commenting and editing the manuscript. W.B.Y contributed to the design of the experiment, analysis of the data and writing the manuscript with the help of Z.J. and Y.J.C. synthesized the $\mathrm{TiO}_{2}$ network nanostructure. X.C. performed the etching treatment with $\mathrm{TiO}_{2}$ films. H.Y.X. carried out the fabrication and the characterization of the solar cells. L.R. contributed to the OCVD measurement and the analysis of the data.

\section{Additional information}

Supplementary information accompanies this paper at http://www.nature.com/ scientificreports

Competing financial interests: The authors declare no competing financial interests

How to cite this article: Wang, H. et al. Significant enhancement of power conversion efficiency for dye sensitized solar cell using 1D/3D network nanostructures as photoanodes. Sci. Rep. 5, 9305; DOI:10.1038/srep09305 (2015).

\section{(c) (i) (5) (2)}

This work is licensed under a Creative Commons Attribution-NonCommercialShareAlike 4.0 International License. The images or other third party material in this article are included in the article's Creative Commons license, unless indicated otherwise in the credit line; if the material is not included under the Creative Commons license, users will need to obtain permission from the license holder in order to reproduce the material. To view a copy of this license, visit http:// creativecommons.org/licenses/by-nc-sa/4.0/ 